\title{
Do Only-children Have Poor Vision? Evidence from China's One-Child Policy
}

\author{
Liqiu Zhao \\ School of Labor and Human Resources, Renmin University of China \\ E-mail: liqiuzh@gmail.com \\ Minghai Zhou (corresponding author) \\ School of Economics, The University of Nottingham Ningbo China and GEP-China \\ E-mail: Minghai.Zhou@ nottingham.edu.cn \\ Telephone: +8657488180215 \\ Fax: +865748818 0125 \\ Address: SSB322, 199 Taikang East Road, Ningbo, 315100, China
}

\begin{abstract}
We acknowledge the National Survey Research Center (NSRC) at Renmin University of China for providing the dataset. Liqiu Zhao acknowledges the financial support from the National Natural Science Foundation of China (Grant No. 71403286). Minghai Zhou acknowledges the financial support from Center of Social Welfare and Governance, Zhejiang University, the Key Base for Philosophy and Social Sciences Research of Zhejiang Province (Grant No. 14JDLB01Z). We thank useful comments from Shihe Fu, Rufei Guo, Fei Wang, Weidong Wang, Daihai Hao and other participants at Educational Process and School Effect Forum of 2016 Annual Conference on Chinese Sociology and 1st Annual Meeting of China Labor Economists Forum. All errors are the authors' own.
\end{abstract}




\title{
Do Only-children Have Poor Vision? Evidence from China's \\ One-Child Policy
}

\begin{abstract}
This paper examines whether only-children have poor vision by exploiting the quasi-natural experiment generated by the Chinese One-Child Policy. The results suggest that being an only-child increases the incidence of myopia by 9.1 percentage points. We further investigate the mechanisms through which being an only-child affects the myopia and find that only-children, as the only hope in a household, receive higher expectations in terms of academic performance and future educational attainment and pressure to succeed in life from parents, which contribute to the increased myopia. We also find that the school quality of only-children is significantly higher than that of non-only-children. This study provides new insights into an important health consequence of One-Child Policy in China.
\end{abstract}

Keywords: Myopia; One-Child Policy; Educational pressure; China JEL: J13; I12 


\section{INTRODUCTION}

The quantity-quality model of Becker and Lewis (1973) suggests that decreases in the quantity of children will induce more resources to be allocated to each child so that the average child quality will increase. A large number of empirical studies have found a significant trade-off between the number of children and child quality, in terms of educational attainment and health, in China (Li et al., 2008; Rosenzweig and Zhang, 2009; Liu, 2014). However, recently, a few studies have investigated the undesirable consequences of being an only-child. For instance, they find that only-children are less trusting, less trustworthy, more risk-averse, less competitive, more pessimistic, and less conscientious (Cameron et al., 2013). Only-children are more depressed and less happy (Park and $\mathrm{Wu}, 2016)$ and have higher probability of being overweight or obese (Zhang et al., 2016). In this paper, we focus on another important health consequence of being an only-child, i.e., short-sightedness or myopia. Specifically, this paper relates the rising prevalence of myopia and the growing number of only-children induced by One-Child Policy, providing new insights into an important health consequence of One-Child Policy in China.

Myopia, known as short-sightedness, causes difficulty in seeing distant objects. The costs of myopia are considerable. First of all, myopia is associated with substantial direct out-of-pocket expenditure (Zheng et al., 2013). Moreover, poor vision negatively affects the academic performance and mental health of students (Glewwe et al., 2016; Yi et al., 2015) and it may further affect adult productivity. Myopia is common in school-aged children, particularly in Asia. China is one of the 
countries with the highest myopia rate in the world, which poses a major health problem. More importantly, myopia has risen dramatically in China recently. As shown by the National Survey on the Constitution and Health of Chinese Students, the prevalence of myopia in junior high school students increased by more than 25 percentage points over the last two decades, from $41.42 \%$ in 1995 to $67.33 \%$ in 2010 (see Figure 1). A large number of studies have attempted to investigate the driving forces of the epidemic. For example, Morgan et al. (2012) find that the rising prevalence of myopia is associated with increasing educational pressures, combined with life-style changes, which have reduced the time children spend outside. The lack of exposure to bright light outdoors most often causes myopia. However, the causes of the rising educational pressures have not been investigated yet in the literature. In this paper, we examine whether the One-Child Policy initiated in 1980 in China is responsible for the increasing educational pressures and thus the rising prevalence of myopia in China.

\section{[Insert Figure 1 here]}

Both genetic and environmental factors contribute to the development of myopia. Ethnicity plays a role in the occurrence of vision problems. Asian, Hispanic children are found to have higher prevalence of myopia than black and white children (Rudnicka et al., 2010). Moreover, children with myopic parents are at higher risk of developing higher degree of myopia than those with no parental myopia (Lim at el., 2014). The environmental factors implicated in myopia include near work, outdoor activities, and nutrition. For instance, near work, such as close reading distance and 
continuous reading, increases the odds of having myopia (Ip et al., 2008). Time spent outdoors is associated with a decreased risk of myopia (Rose et al., 2008; Sherwin et al., 2012; Guo et al., 2013), due to the protective effects of bright light. Diet and nutrition are also environmental determinants of myopia and myopic progression. A recent study by Lim et al. (2010) finds that higher saturated fat and cholesterol are correlated with higher risk of myopia. Among these risk factors of myopia, genetic factors do not explain the rising prevalence of myopia in China from 1990s, as gene pools just do not change in two generations. The increased computer use may lead to increased myopia. However, a number of studies have examined the effect of computer use on myopia and found no significant correlation (Mutti and Zadnik, 1996; Rose et al., 2008). There is clear evidence that a high and increasing prevalence of myopia in East Asia is driven by increasing educational pressures and urbanization (Morgen et al., 2012).

In this paper, we exploit the quasi-natural experiment generated by One-Child Policy in China to identify the causal effect of being an only-child on the odds of having myopia. We find that being an only-child increases the incidence of myopia by approximately 9.1 percentage points and the positive only-child effect is not due to the birth order effect. As shown by the Population Census data in China, the share of only-children among junior high school students increased from 5\% in 1990 to $42.7 \%$ in 2005. This implies that the growing share of only-children leads to a 3.43 percentage points increase in the incidence of myopia during this period, which explains approximately $15 \%$ of the total increase in the prevalence of myopia in 
China.

We further examine the potential mechanisms through which being an only-child affects myopia. We find that only-children, as the only hope in a household, receive higher expectations from parents in terms of academic performance and future educational attainment, which contribute to the increased myopia. The findings are consistent with the evidence found in the literature, that is, only-children receive more attention from parents as well as higher expectations and pressure to succeed in life (Roberts and Blanton, 2001). We also find that the school quality of only-children is significantly higher than that of non-only-children. In order to better understand the mechanisms, we further investigate the impact of being an only-child on time allocation of students. However, we find no significant difference in time allocation between only-children and non-only-children. Finally, we find that the expectations of parents, school quality and time spent on school assigned homework significantly contribute to the myopia. After controlling for parental expectations, school quality and time allocation, the impact of being an only-child on myopia become insignificant.

The contributions of this paper are two-folded. Firstly, the prevalence of myopia has markedly increased within the past two decades in China. This is the first study which relates the rising prevalence of myopia and the growing number of only-children induced by One-Child Policy. Secondly, this paper exploits the quasi-natural experiment generated by the One-Child Policy in China to identify the causal effect of being an only-child on the odds of having myopia. 
The remainder of this paper is organized as follows. Section 2 outlines the identification strategy. Section 3 describes the data used in the analysis. Section 4 reports the empirical results and discusses potential channels through which being an only-child affects the odds of having myopia. Section 5 concludes.

\section{EMPIRICAL SPECIFICATION}

To examine the impact of single child on myopia, we estimate the following regression:

$$
\text { Myopia }_{i}=\beta_{0}+\beta_{1} \text { Single }_{i}+\beta_{2} X_{i}+\beta_{3} H_{i}+D_{c}+\varepsilon_{i}
$$

where Myopia $_{i}$ is a dummy variable which equals one if the student is short-sighted. Single $_{i}$ is an indicator for being an only-child, and the coefficient of interest would be $\beta_{1} . X_{i}$ is a vector of student characteristics, including gender, age, age squared, ethnicity, grade, hukou type, local resident dummy, and a dummy indicating whether the student had any serious disease before primary school. $H_{i}$ refers to parental and household characteristics, including parental educational level, party membership, occupation type, household economic condition, whether the household receives Dibao subsidy, the presence of sick or disabled household members who need long-term care, the access to tap water and the use of improved sanitation facilities. ${ }^{1}$ For the occupation type, we use a dummy variable indicating whether parents have professional occupations. More specifically, we define professional occupation as government official, general and senior manager in enterprises, senior professional

\footnotetext{
${ }^{1}$ The Dibao program is also called the Minimum Living Standard Guarantee scheme in China.
} 
(including doctor, professor, lawyer, engineer, and etc.), and define non-professional occupation as skilled worker (including craftsman, driver, and etc.), un-skilled worker, service worker, self-employed, farmer and unemployed. Household economic condition, which measures household income, comes from responses to the following survey question: “How's your family's current economic condition?”. Responses were on a five-point scale, ranging from very poor to very rich. In Equation (1), we control for dummies of economic condition. To control for observable and unobservable characteristics of a county/district, we also include county/district dummies $D_{c}$ in the regression. $\varepsilon_{i}$ is the error term.

If being a single child is exogenous, the effect of single child can be estimated consistently by ordinary least squares (OLS). However, the number of children in a household is determined by parents. Parents who value quality (e.g., education and health) may prefer an only-child. Moreover, parental preference for child quality might affect children's likelihood of being myopic. On the one hand, parents who value education may impose higher educational pressures on their only-children. Due to the higher educational pressure induced by parental preference, these only-children tend to work hard and have intensive near work, such as close reading distance and continuous reading, which increases the odds of having myopia (Ip et al., 2008). Thus, only-child and myopia may both be the consequences of parental preference for child quality. On the other hand, parents who value quality may also concern over health of their children. Thus, they tend to provide sufficient nutrition and suitable studying environment to their children, which may reduce the odds of having myopia. Parental 
preference is the unobserved variable, which is associated with both only-child indicator and myopia. Consequently, OLS estimator may suffer from the omitted variable bias. In other words, the coefficient on Single $_{i}$ in Equation (1) would pick up not only the effect of being a single child but also the effect of any omitted family background variables, for example, parental preference for child quality.

In this paper, we use the exogenous imposition of the One-Child Policy to identify the causal impact of being an only-child, net of family background effects. The One-Child Policy was initiated in 1980. At the early stage of the implementation of the One-Child Policy, the second birth was strictly forbidden. Because of the gendercide caused by the strict One-Child Policy, in 1984 the central government relaxed the strict One-Child Policy and allowed rural couples to have a second child if the first child was a girl, which is referred to as 1.5 child policy. ${ }^{2}$ In China, most parents have a very strong desire to have at least one son. As rural couples can have a second birth if the first birth was a daughter, they do not use sex-selective abortion for their first pregnancies but tend to use sex-selective abortion to ensure a boy in the second pregnancy. Despite the overall imbalanced sex ratio in China, the sex ratio of the first birth is quite normal and the gender of the first child could be viewed as exogenous (Ebenstein 2010, 2011; Chen et al., 2013). Table 1 reports the sex ratio at birth in China by birth order during 1995-2000 based on the $0.1 \%$ sample of the 2000 Population Census data. The sex ratio of the first born child is 106.44 and 105.55 in

\footnotetext{
2 The policy imposes a 2- or 3-child policy limit for provinces in remote areas. The policy also grants exclusions to various groups, including Chinese ethnic minorities and those employed in dangerous occupations (Ebenstein, 2010). See Wang et al. (2017) for a review of the historical evolution of China's family planning policies. However, the validity of our identification strategy does not rely on whether One-Child Policies in rural China are universal or not.
} 
urban and rural areas, respectively, which is around the natural sex ratio across world populations. The results in Table 1 indicate that parents may not engage in sex selection for their first birth, and the gender of the firs-born child tends to be exogenous to the myopia rates. Moreover, the 1.5 child policy in rural China implies that families tend to have a second child if the first-born child is a daughter. Thus, the gender of the first-born child can be used as an instrumental variable (IV) for single child.

\section{[Insert Table 1 here]}

Additionally, the enforcement of the one-child policy varies across regions and across years. We can measure the strength of the enforcement of the one-child policy by using the average monetary penalty rate for one unauthorized birth in the provincial-level panel from 1980-2000 from Ebenstein (2010). ${ }^{3}$ The fine rates are formulated in years of household income (Ebenstein, 2010; Huang et al., 2016; Huang and Zhou, 2015). Figure A.1 plots the fertility penalty from 1980 to 2000 in each province, suggesting that fine rates in different provinces follow different patterns, both in terms of timing and magnitude. The geographical and temporal variances of fine rates help us identify the effects of the One-Child Policy in the empirical analysis. Because a pregnancy usually lasts for 9 months, parents' decision to have a child, if any, should be made close to a year in advance. We therefore match the CEPS data with the policy fine (at provincial level) one year before the birth year of students. The fine rates one year before the birth year should be exogenous to the myopia rate.

\footnotetext{
${ }^{3}$ Though the monetary penalty is one aspect of the policy, it can capture key elements of the variation in the strictness of the policy (Gu et al., 2007).
} 
The gender of the first-born child and lagged fine rates in the corresponding province and year can act as instruments for single child indicator, which can be illustrated as the following regression:

$$
\text { Single }_{i}=\gamma_{0}+\gamma_{1} \text { first }_{\text {birth }}+\gamma_{2} \text { fine }_{\text {birth }}+\gamma_{3} X_{i}+\gamma_{4} H_{i}+D_{c}+\eta_{i}
$$

\section{DATA}

We use data from the China Education Panel Survey (CEPS) conducted by National Survey Research Center (NSRC) at Renmin University of China. ${ }^{4}$ The CEPS is a national, representative, longitudinal survey of junior high school students in China. The baseline survey was conducted in the 2013-2014 school year starting with two cohorts - the 7th and 9th graders. The CEPS applies a stratified, multistage sampling design with probability proportional to size (PPS), randomly selecting a school-based, nationally representative sample of approximately 20,000 students in 438 classrooms of 112 schools in 28 county-level units in mainland China. The CEPS administers 5 different questionnaires to (1) the sample students, (2) their parents, (3) their homeroom teachers, (4) their main subject teachers, and (5) their school administrators.

\subsection{Definition of myopia}

The definition of myopia comes from students' responses to the following survey question "Are you nearsighted?". The answers to this question include: (1) Yes, I know the degree of myopia; (2) Yes, but I do not know the degree of myopia; (3) No.

\footnotetext{
${ }^{4}$ Detailed information about the CEPS survey is available at the CEPS website http://chinaeps.org/index.php?r=index/index\&hl=en.
} 
If the answer to this equation is (1), then the student is required to report the degree of myopia in both eyes. We define that a student is nearsighted if his/her answer to this question is "Yes" no matter whether he/she knows the degree of myopia or not. So the myopia status in this paper is self-reported. ${ }^{5}$

Due to the nature of the data set, we cannot observe the true value $M y o p i a_{i}^{*}$, but an observable measure Myopia $_{i}$, which is self-reported by students. We define

$$
\text { Myopia }_{i}-\text { Myopia }_{i}^{*}=e
$$

where $e$ is the measurement error, partly depending on whether a student has had an eye examination recently. Consequently, the equation that we can estimate is,

$$
\text { Myopia }_{i}=\beta_{0}+\beta_{1} \text { Single }_{i}+\beta_{2} X_{i}+\beta_{3} H_{i}+D_{c}+e+\varepsilon_{i}
$$

If only-children tend to have eye examinations and, thus, are more likely to report having myopia, measurement error bias may arise. Nevertheless, if whether a student has had an eye examination recently is not significantly associated with the gender of the first-born child and fine rates, which are instrumental variables for single child indicator, the estimates using IV approach are consistent. The results in Table A.1 confirm that the indicator whether a student has had an eye examination recently is not significantly associated with the gender of the first-born child and fines rates.

\subsection{Myopia in China}

\footnotetext{
${ }^{5}$ As most students in China have routine physical examination every year, including eye examination, normally students know their myopia status. More specifically, the CEPS shows that approximately $80 \%$ of students have eye examinations.
} 
Table 2 shows the prevalence of myopia in junior high school students in China based on the CEPS survey. $59 \%$ of the junior high school students are short-sighted; however, only approximately $50 \%$ of myopic students know their degree of myopia. ${ }^{6}$ The myopia rates are increasing with the years of schooling, from $53 \%$ for the 7 th graders to $66 \%$ for the 9 th graders. Interestingly, the incidence of myopia is higher for only-children, that is, $66 \%$ for only-children, compared to $54 \%$ for children with one or more siblings. Additionally, students in urban areas and girls are more likely to be short-sighted.

\section{[Insert Table 2 here]}

\subsection{Summary statistics}

The characteristics of only-children and children with one or more siblings (non-only-children) are reported in Table 3. As expected, only-children are more likely to come from households with a first born boy. Only-children tend to be boy, younger, and to have urban hukou. Parents of only-children tend to be more educated, to be party members, to have professional occupations and to be richer. We also find that only-children and non-only-children have different time use patterns. Only-children tend to sleep less, and spend significantly more time on homework assigned either by teachers or parents, extracurricular classes, but less time on watching TV. Specifically, non-only-children spend approximately 2.5 hours per day on homework, including those assigned both by parents and teachers, while only-children spend 3 hours per day on homework, both of which are substantially

\footnotetext{
${ }^{6}$ The percentage of myopic students who know their degree of myopia is comparable to the percentage of myopic students who wear glasses found in He et al. (2007).
} 
higher than the maximum hours, i.e., 1.5 hours, set by the Ministry of Education in China in 2008. Parents have significantly higher long-term expectation on only-children in terms of future educational attainment. The school quality of only-children is significantly higher than that of non-only-children.

[Insert Table 3 here]

\section{RESULTS}

\subsection{Baseline Results}

Table 4 presents the effect of single child on myopia applying both OLS and IV estimation strategy. The results of OLS estimation suggest that being an only-child has a significantly positive effect on the odds of having myopia. Specifically, compared to students who have one or more siblings, being an only-child increases the incidence of myopia by 2.6 percentage points. As previously discussed, OLS estimate may be biased because only-child is largely a choice of parents. Parents who value quality may prefer an only-child. Thus, the coefficient of single child may also pick up the effect of omitted family background variables.

\section{[Insert Table 4 here]}

In order to address the potential endogeneity issue, we apply the gender of the first-born child and one-year lagged provincial fine rates as instrumental variables for the only-child indicator. As expected, if the first-born child is a boy, the incidence of being an only-child increases by 22 percentage points; if provincial fine rates, formulated in years of household income, increases by 1, the probability of being an 
only-child increases by 2 percentage points. The IV estimates in column (3) show that being an only-child increases the incidence of myopia by 9.1 percentage points, which is substantially larger in magnitude than the OLS estimate which is shown in column (4) of Table 4. As discussed in Section 2, the OLS estimator can be biased downwards or upwards. The results in column (4) suggest that the downward bias tends to dominate the upward bias. Finally, various tests, such as under-identification test, weak identification test and over-identification test, all suggest that these two IVs are valid.

For both OLS and IV results, the coefficients of other control variables are consistent and as expected. The significantly negative coefficient of boy dummy implies that girls are more likely to be myopic than boys, which is consistent with the existing findings in the literature (for example, Fan et al., 2004; Rudnicka et al., 2016, among others). One possible explanation would be that girls tend to spend more time on homework, reading and other near-work activities, whereas boys spend more time on outdoor activities (Lu et al., 2009). The subsequent increase in near-work predisposes girls to myopia development. Compared to the 7 th graders, the 9th graders are approximately 13 percentage points more likely to have myopia problems. Interestingly, after controlling for the grade dummy, age has no significant effect on the incidence of myopia, implying that study load other than age matters for being myopic.

Family backgrounds also play roles in shaping children's myopia status. We consistently find that fathers with professional occupations significantly increase the 
incidence of myopia of their children. Nevertheless, the educational level of parents does not have significant effects on the likelihood of myopia. Students from households which receive Dibao subsidy are less likely to be myopic. Moreover, after controlling for Dibao subsidy dummy, family economic status does not significantly influence the incidence of myopia.

The baseline results suggest that the vision impact of One-Child Policy is remarkable: being an only-child increases the incidence of myopia by 9.1 percentage points. A number of studies find that the undesirable consequences of One-Child Policy on other health outcomes are also sizeable. For example, Zhang et al. (2016) find that being an only-child increases the probability of being overweight by 9 percentage points. Park and Wu (2016) show that being an only child increases one's depression by 0.59 standard deviations (SD) and decreases one's happiness by 0.56 SD.

\subsection{The Degree of Myopia}

In Section 4.1, we apply an indicator, i.e., myopia status, to measure nearsightedness. However, in the survey, students who are nearsighted and know their degree of myopia are required to report the degree of myopia in both eyes. ${ }^{7}$ In this section, we apply the information on the degree of nearsightedness to investigate whether being an only-child affects the level of myopia.

\footnotetext{
${ }^{7}$ In the sample, approximately $50 \%$ of students who are nearsighted do not know the exact degree of myopia. Having information on the degree of myopia tend to be related with only-child status, as only-children who are nearsighted, are more likely to wear glasses and thus have their eyeglasses prescriptions. This is the major concern of self-reported degree of myopia. Nevertheless, myopia status, whose measurement error is less likely to be correlated with only-child status, is less problematic. Thus, our main results rely on the self-reported myopia status.
} 
To this end, we follow Cline et al. (1997) and classify myopia by diopter or degree as follows: $1=$ normal or emmetropic $(0) ; 2=$ mild nearsightedness $(-0.25$ to -3.00 diopters $) ; 3=$ moderate nearsightedness $(-3.00$ to -6.00 diopters $) ; 4=$ severe nearsightedness (-6.00 diopters or higher). ${ }^{8}$ We analyze the effect of being an only-child on the degree of myopia with an IV-ordered probit model. The marginal effects from the IV-ordered probit model are reported in Table 5, suggesting that only-child tends to have worse vision in both left and right eyes.

[Insert Table 5 here]

\subsection{Robustness Checks}

The significant and positive effect of only-children on the odds of myopia found in Section 4.1 may be simply due to the birth order effect. An only-child is the first-born child in a household. A number of studies show that first-born children are more likely to be myopic than their younger siblings, because first-born children receive more attention from their parents in terms of their education (Morgan and Cotch, 2013; Guggenheim and Williams, 2015). We test the robustness of our results by controlling for birth order in Equation (1).

In column (1) of Table 6, we first control for the number of siblings in the regression and find that it reduces the incidence of myopia, though statistically insignificant. In column (2), to capture the non-linear effects of the number of siblings, we use dummies of the number of siblings rather than a continuous variable. Nevertheless, as we do not have enough instruments for the dummies, we can only

\footnotetext{
${ }^{8}$ Students who did not report their degree of myopia are considered to be emmetropia.
} 
apply OLS estimation here. The coefficients of dummies show that the negative effect of the number of siblings becomes greater as the number increases. In column (3), we only control for the birth order of students and find a negative effect of birth order on the incidence of myopia, though statistically insignificant.

\section{[Insert Table 6 here]}

In order to disentangle the effect of the number of siblings and birth order effect, in column (4) of Table 6 we control for both the number of siblings and dummies for birth order. Given the number of siblings in a household, which is instrumented with the gender of the first-born child and one-year lagged provincial fine rates, the birth order of a child is exogenous. We find a significantly negative effect of the number of siblings on the incidence of myopia after controlling for the birth order effect. This implies that, given the same birth order, the presence of an extra sibling reduces the incidence of myopia. For example, the coefficient of the number of siblings reflects the difference in the odds of myopia between first-born child without siblings (i.e., only-child) and first-born child with siblings (i.e., non-only-child). Therefore, we confirm that the positive one-child effect is not due to birth order effect. Additionally, the coefficients of dummies for birth order indicate that middle child has the highest incidence of myopia.

\subsection{Heterogeneous Effects}

To better understand the consequence of being an only-child on myopia, we further investigate whether the effect of being an only-child on the incidence of myopia 
differs across sub-groups in our data. To this end, we divide the sample by gender, grade, and household economic condition. The results are reported in Table 7. Note that the statistical test of differences in coefficients across groups reveals that there is no significant heterogeneity in the only-child impacts. Thus, the results in Table 7 should be interpreted with caution.

\section{[Insert Table 7 here]}

Because of son preference in China, the only-child effects may be larger for boys. However, the estimates for girls and boys in columns (1) and (2) of Table 7 indicate no significant difference in one-child effects across gender.

The impact of single child may be greater for the 9th graders due to the longer exposure to higher educational pressure. We report the results for the 7th graders and 9th graders separately in columns (3) and (4) of Table 7 and find that one-child effect is significant and stronger only for the 7 th graders whereas there is no significant effect for the 9th graders. Although only-children do not have a significantly higher incidence of myopia in the 9th grade, they are probably at higher risk of developing higher degree of myopia as only-children became myopic at an earlier age. Table A.2 suggests that being an only-child is significantly associated with greater risk of having severe nearsightedness (-6.00 diopters or higher) for the 9th graders. However, the relationship is insignificant for the 7 th graders.

Parents with different socio-economic status may place different expectations on their children. For example, parents in poor families may emphasize the role of 
education as a mean of alleviating poverty and thus have higher expectation on only-children. We next examine whether one-child impacts on myopia are stronger for students from poor families. As shown in the last column of Table 7, only-children have higher incidence of myopia in poor families. However, the impact of being an only-child on the incidence of myopia is insignificant for students from families whose economic conditions are medium or above (see column (5) in Table 7).

\subsection{Channels}

The exogenous decline in fertility induced by the One-Child Policy in China forces parents to place "all their eggs in one basket" with only-children. Only-children, who are the only hope in a household, receive more attention and resources from their parents. Accordingly, they also receive higher expectations and pressures from parents to succeed in life. Thus, only-children tend to work hard and are more likely to be myopic. In order to test the above mechanisms, we consider two dimensions of expectations, i.e., parents' short-term expectations on children's relative ranking of test scores in the class and parents' long-term expectations on children's future educational attainment. For the short-term expectation, students are asked whether their parents have specific requirements on their academic performance measured by their relative ranking of test scores. With regard to the long-term expectation, students are asked which educational attainment their parents hope that they will achieve in the future, for example, high school, college, or master. Note that both the short-term and long-term expectations of parents are reported by students, as it is the perceived parental expectation that influences the behavior of students. 
In order to deal with the endogeneity issue, we apply IV-ordered probit model for two categorical expectation measures. Only-child indicator is instrumented with the gender of the first-born child and provincial fine rates. The first two columns in Table 8 present the impacts of single child on both parents' short- and long-term expectations. We find that parents hold significantly higher expectations if they have an only-child. This suggests that the effects of single child on myopia could go through the channel by raising expectations of parents having an only-child. In addition, we find that not only children's characteristics, but also parents' features matter for parental expectations.

\section{[Insert Table 8 here]}

Parents who place higher expectations on their only-children may also choose higher school quality for their children. The last column in Table 8 presents the impact of single child on the choice of school quality. School quality is measured by the relative ranking of junior high schools in a county/district. As above, we apply an IV-ordered probit model here. We find that parents of single child tend to choose high quality schools. Since school quality is determined by performance-based evaluation, the only-child who is more likely to be in high quality schools will bear heavy study load and exert more study effort, thus in turn increases the likelihood of having myopia problems. Additionally, we also find that the characteristics of students, parents and family economic conditions affect the choices of schools. Better educated parents and parents with professional occupations tend to choose higher school quality for their children. 
As discussed above, the higher incidence of myopia for only-children may go through higher expectations from parents by raising students' study effort. Therefore, we further test whether the only-child has different time allocation from non-only-child. We also apply both the gender of the first born child and fine rates as IVs for single child indicator to address the endogeneity issue. Table 9 presents the impact of the only-child on time allocation in both weekdays and weekends. We find no significant difference in time allocation between only-children and non-only-children both in weekdays and weekends. ${ }^{9}$ The insignificant impacts of single child on time allocation are probably due to the substantial measurement errors in time use data reported by students. In the time use survey of CEPS, students were asked to recall how they spent their time on various activities in the last week. It requires respondents to perform two difficult tasks: to recall their activities in the last week and to carry out an appropriate form of averaging. The recall error and the inappropriate form of averaging might lead to substantial measurement error.

\section{[Insert Table 9 here]}

Finally, we test whether parental expectations, choices of schools and students' time allocation contribute to the increased myopia. To this end, we control for parental expectations, choices of schools and students' time allocation in the myopia regression in Table 10. We find that the effect of only-child on myopia is captured by newly added controls. Higher parental expectations and school quality are significantly associated with higher incidence of myopia. More school assigned

\footnotetext{
${ }^{9}$ One exception is that only-children tend to spend significantly less time on doing homework assigned by parents in weekends.
} 
homework and internet surfing increase the likelihood of having myopia problems. This further supports our argued mechanism that the one-child policy effect on myopia is mainly through parental expectations and students' study effort.

[Insert Table 10 here]

\section{CONCLUSION}

The traditional quantity-quality trade-off model implies that only-children receive more resources and thus have higher educational attainment and health. In this paper, we show that only-children also receive higher expectations and pressures from parents to succeed in life, which induces a high incidence of myopia. This paper relates the growing number of only-children induced by One-Child Policy and the rising prevalence of myopia, providing new insights into an important health consequence of One-Child Policy in China. We exploit the quasi-natural experiment generated by One-Child Policy in China to identify the causal effect of being an only-child on the odds of myopia. We find that being an only-child increases the incidence of myopia by approximately 9 percentage points.

We further examine the potential mechanisms through which being an only-child affects the incidence of myopia. We find that only-children, as the only hope in a household, receive higher expectations from parents in terms of academic performance and future educational attainment, which contribute to the increased myopia. We also find significantly higher school quality of only-children, as one of the consequences of higher parental expectation. However, only-children do not have 
significantly different time allocation to various activities. Moreover, we find that the expectations of parents, school quality and time spent on teacher assigned homework significantly contribute to the myopia. 


\section{REFERENCES}

Becker, G., \& Lewis, G. (1973). On the interaction between the quantity and quality of children. Journal of Political Economy, 81(2), S279-S288.

Cameron, L., Erkal, N., Gangadharan, L., \& Meng, X. (2013). Little emperors: behavioral impacts of China's one-child policy. Science, 339, 953-957.

Chen, Y., Li, H., \& Meng, L. (2013). Prenatal sex selection and missing girls in China: evidence from the diffusion of diagnostic ultrasound. The Journal of Human Resources, 48 (1), 36-70.

Cline, D., Hofstetter, H., \& Griffin, J. (1997). Dictionary of Visual Science (4th ed.). Boston, MA: Butterworth-Heinemann.

Ebenstein, A. (2010). The "missing girls" of China and the unintended consequences of the one child policy. Journal of Human Resources, 45 (1), 87-115.

Ebenstein, A. (2011). Estimating a dynamic model of sex selection in China. Demography, 48, 783-811.

Fan, D., Lam D., Lam, R., Lau, J., Chong, K., Cheung, E., Lai, R., \& Chew, S. (2004). Prevalence, incidence, and progression of myopia of school children in Hong Kong. Invest Ophthalmol Vis Sci, 45(4), 1071-1075.

Glewwe, P., Park, A., \& Zhao, M. (2016). A better vision for development: eyeglasses and academic performance in rural primary schools in China. Journal of Development Economics, 122, 170-182. 
Gu, B., Wang F., Guo, Z., \& Zhang, E. (2007). China's local and national fertility policies at the end of the twentieth century. Population and Development Review, 33(1), 129-147.

Guggenheim, J., \& Williams, C. (2015). Role of educational exposure in the association between myopia and birth order, JAMA Ophthalmology, 133(12), 1408-1414.

Guo, Y., Liu, L., Xu, L., Lv, Y., Tang, P., Feng, Y., Meng, M., \& Jonas, J. (2013). Outdoor activity and myopia among primary students in rural and urban regions of Beijing, Ophthalmology, 120(2), 277-283.

He, M., Huang, W., Zheng, Y., Huang, L., \& Ellwein, L.B. (2007). Refractive error and visual impairment in school children in rural southern China, Ophthalmology, 114(2), 374-382.

Huang, W., Lei, X., Zhao, Y. (2016). One-child policy and the rise of man-made twins. Review of Economics and Statistics, 98(3), 467-476.

Huang, W., \& Zhou, Y. (2015). One-child policy, marriage distortion, and welfare loss. IZA Discussion Paper, No. 9532.

Ip, J., Saw, S., Rose, K., Morgan, I., Kifley, A., Wang, J., \& Mitchell, P. (2008). Role of near work in myopia: findings in a sample of Australian school children. Investigative Ophthalmology \& Visual Science, 49(7), 2903-2910.

Rudnicka, A., Owen, C., Nightingale, C., Cook, D., \& Whincup, P. (2010). Ethnic differences in the prevalence of myopia and ocular biometry in 10- and 11-year-old children: the child heart and health study in England (CHASE). 
Investigative Ophthalmology \& Visual Science, 51(12), 6270-6276.

Rudnicka, A., Kapetanakis, V., Wathern, A., Logan, N., Gilmartin, B., Whincup, P., Cook, D., \& Owen, C. (2016). Global variations and time trends in the prevalence of childhood myopia, a systematic review and quantitative meta-analysis: implications for aetiology and early prevention, British Journal of Ophthalmology, forthcoming.

Rose, K., Morgan, I., Smith, W., Burlutsky, G., Mitchell, P., \& Saw, S. (2008). Myopia, lifestyle, and schooling in students of Chinese ethnicity in Singapore and Sydney. Arch Opthalmol, 126(4), 527-530.

Li, H., Zhang, J., \& Zhu, Y. (2008). The quantity-quality trade-off of children in a developing country: identification using Chinese twins. Demography, 45(1), 223-243.

Lim, L., Gazzard, G., Low, Y., Choo, R., Tan, D., Tong, L., Wong, T., \& Saw, S. (2010). Dietary factors, myopia, and axial dimensions in children. Ophthalmology, 117(5), 993-997.

Lim, L., Gong, Y., Ah-Kee, E., Xiao, G., Zhang, X., \& Yu, S. (2014). Impact of parental history of myopia on the development of myopia in mainland China school-aged children. Ophthalmology and Eye Disease, 24(6), 31-35.

Liu, H. (2014). The quality-quantity trade-off: evidence from the relaxation of China's one-child policy. Journal of Population Economics, 27(2), 565-602.

Lu, B., Congdon, N., Liu, X., Choi, K., Lam, D.S.C., Zhang, M., Zheng, M., Zhou, Z., Li, L., Liu, X., Sharma, A., Song, Y. (2009). Associations Between Near Work, 
Outdoor Activity, and Myopia Among Adolescent Students in Rural China, Arch Ophthalmol, 127(6),769-775.

Morgan, I., Kyoko, O., \& Saw, S. (2012). Myopia. The Lancet, 379 (9827), $1739-1748$.

Morgan, I., \& Cotch, M. (2013). Birth order and myopia: what are the messages to readers. Ophthalmic Epidemiol, 20(6), 333-334.

Mutti, D., \& Zadnik, K. (1996). Is computer a risk factor for myopia? Journal of the American Optometric Association, 67(9), 521-530.

Park, A., \& Wu, L. (2016). Are Only Children More Depressed? Evidence from China's One Child Policy, Working Paper.

Roberts, L., \& Blanton, P. (2001). 'I always knew mom and dad loved me best': experiences of only children. Journal of Individual Psychology, 57(2), 125.

Rosenzweig, M., \& Zhang, J. (2009). Do population control policies induce more human capital investment? Twins, birth weight and China's "one-child". Review of Economic Studies, 76(3), 1149-1174.

Sherwin, J., Reacher, M., Keogh, R., Khawaja, A., Mackey, D., \& Foster, P. (2012). The association between time spent outdoors and myopia in children and adolescents: a systematic review and meta-analysis. Ophthalmology, 119(10): 2141-51.

Wang, F., Zhao, L., \& Zhao, Z. (2017). China's Family Planning Policies and Their Labor Market Consequences, Journal of Population Economics, 30(1), 31-68.

Yi, H., Zhang, L., Ma, X., Congdonc, N., Shi, Y., Pang, X., Zeng, J., Wang, L., 
Boswell, M., \& Rozelle, S. (2015). Poor vision among China's rural primary school students: prevalence, correlates and consequences. China Economic Review, 33, 247-262.

Zhang, J., Xu, P., \& Liu, F. (2016). One-child policy and childhood obesity. China Economic Review, forthcoming, doi:10.1016/j.chieco.2016.05.003

Zheng, Y., Pan, C., Chay, J., Wong, T., Finkelstein, E., \& Saw, S. (2013). The economic cost of myopia in adults aged over 40 years in Singapore, Investigative Ophthalmology \& Visual Science, 54(12), 7532-7537. 


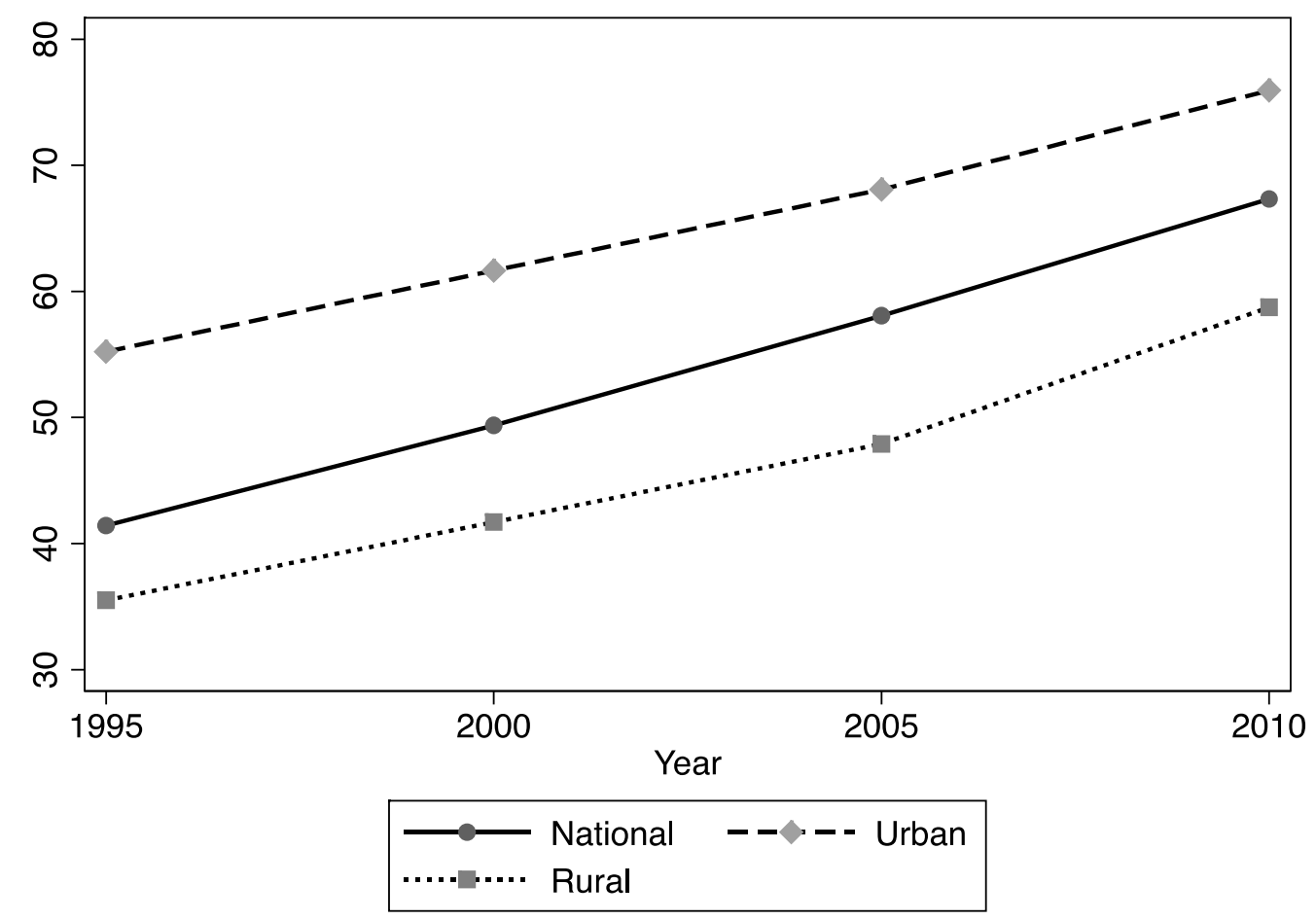

FIGURE 1 The prevalence of myopia of junior high school students in China:

$1995-2010$

Source: The National Survey on the Constitution and Health of Chinese Students 1995, 2000, 2005 and 2010. 
TABLE 1 Sex ratio at birth in China by birth order: 1995-2000

\begin{tabular}{llll}
\hline Birth order & Urban & Rural & All \\
\hline First child & 106.44 & 105.55 & 105.85 \\
Second child & 134.19 & 149.44 & 148.32 \\
Third child & 179.56 & 163.64 & 163.99 \\
\hline Average of all birth orders & 110.39 & 125.23 & 122.07 \\
\hline Notes: based on 2000 Population Census in China. & &
\end{tabular}


TABLE 2 The prevalence of myopia among junior high school students in China

\begin{tabular}{lccc}
\hline & Mean & S.D. & $\begin{array}{c}\text { Percentage of } \\
\text { myopic students } \\
\text { who know the } \\
\text { degree }\end{array}$ \\
\hline $\begin{array}{llc}\text { All } \\
\text { \# of siblings }\end{array}$ & 0.59 & 0.49 & $50.13 \%$ \\
Only-child & 0.66 & 0.47 & $54.49 \%$ \\
$\begin{array}{l}\text { Non only-child } \\
\text { Hukou type }\end{array}$ & 0.54 & 0.50 & $46.06 \%$ \\
Urban & & & \\
Rural & 0.65 & 0.48 & $54.56 \%$ \\
Gender & 0.55 & 0.50 & $45.81 \%$ \\
Girl & & & \\
Boy & 0.64 & 0.48 & $49.43 \%$ \\
Grade & 0.54 & 0.50 & $50.92 \%$ \\
$7^{\text {th }}$ grade & & & \\
$9^{\text {th }}$ grade & 0.53 & 0.50 & $48.08 \%$ \\
\hline
\end{tabular}

Notes: based on China Education Panel Survey (CEPS) 2013-2014. 
TABLE 3 Summary Statistics

\begin{tabular}{|c|c|c|c|c|c|}
\hline \multirow[b]{3}{*}{ Variables } & (1) & (2) & (3) & (4) & \multirow{3}{*}{$\begin{array}{c}(5) \\
\text { Diff }\end{array}$} \\
\hline & \multicolumn{2}{|c|}{ Non-only-child } & \multicolumn{2}{|c|}{ Only-child } & \\
\hline & Mean & S.D. & Mean & S.D. & \\
\hline \multicolumn{6}{|l|}{ Student characteristics } \\
\hline Short-sighted & 0.540 & 0.498 & 0.656 & 0.475 & $0.116^{* * *}$ \\
\hline First birth = boy & 0.360 & 0.480 & 0.557 & 0.497 & $0.198 * * *$ \\
\hline Boy & 0.483 & 0.500 & 0.557 & 0.497 & $0.074 * * *$ \\
\hline Age & 14.64 & 1.281 & 14.37 & 1.166 & $-0.268 * * *$ \\
\hline Han ethnicity & 0.886 & 0.318 & 0.948 & 0.223 & $0.062 * * *$ \\
\hline Local resident & 0.792 & 0.406 & 0.858 & 0.349 & $0.066^{* * *}$ \\
\hline Rural hukou & 0.712 & 0.453 & 0.335 & 0.472 & $-0.378 * * *$ \\
\hline Any serious disease before primary school & 0.110 & 0.313 & 0.0678 & 0.251 & $-0.042 * * *$ \\
\hline \multicolumn{6}{|l|}{ Parental and household characteristics } \\
\hline Education of father & 9.302 & 2.599 & 11.59 & 3.235 & $2.293 * * *$ \\
\hline Education of mother & 8.281 & 3.165 & 11.17 & 3.308 & $2.885^{* * *}$ \\
\hline Party member & 0.0802 & 0.272 & 0.178 & 0.383 & $0.098 * * *$ \\
\hline Professional occupation (father) & 0.103 & 0.305 & 0.294 & 0.455 & $0.190 * * *$ \\
\hline Professional occupation (mother) & 0.0542 & 0.226 & 0.243 & 0.429 & $0.189 * * *$ \\
\hline Household economic condition & 2.722 & 0.645 & 2.937 & 0.508 & $0.215^{* * *}$ \\
\hline Sick/disabled household members & 0.144 & 0.351 & 0.0996 & 0.299 & $-0.044 * * *$ \\
\hline Tap water & 0.818 & 0.386 & 0.938 & 0.241 & $0.120 * * *$ \\
\hline Improved sanitation facilities & 0.790 & 0.407 & 0.915 & 0.279 & $0.125^{* * *}$ \\
\hline \multicolumn{6}{|l|}{ Time allocation of students } \\
\hline Sleeping hours & 8.076 & 1.018 & 7.863 & 1.026 & $-0.213^{* * *}$ \\
\hline Hours spent on homework assigned by teachers & 2.011 & 1.360 & 2.349 & 1.251 & $0.338 * * *$ \\
\hline Hours spend on homework assigned by parents & 0.492 & 0.831 & 0.628 & 0.909 & $0.137 * * *$ \\
\hline Hours spent on extra class & 0.142 & 0.462 & 0.241 & 0.597 & $0.099 * * *$ \\
\hline Hours spent on sports & 0.659 & 0.719 & 0.678 & 0.719 & $0.020 *$ \\
\hline Hours spent on watching TV & 0.725 & 0.941 & 0.572 & 0.835 & $-0.154 * * *$ \\
\hline Hours spent on surfing the internet & 0.390 & 0.711 & 0.375 & 0.682 & -0.016 \\
\hline \multicolumn{6}{|l|}{ Expectations and school quality } \\
\hline Expectation: academic performance & 2.813 & 0.932 & 2.834 & 0.885 & 0.020 \\
\hline Expectation: educational attainment & 3.848 & 0.987 & 4.092 & 0.849 & $0.244 * * *$ \\
\hline School quality & 3.820 & 0.866 & 4.112 & 0.759 & $0.292 * * *$ \\
\hline
\end{tabular}

Notes: based on China Education Panel Survey (CEPS) 2013-2014. Column (5) shows the $t$-Test of difference between only-children and non-only-children. $\mathrm{p}<0.01, * * \mathrm{p}<0.05, * \mathrm{p}<0.1$. 
TABLE 4 Impact of only child on myopia status

\begin{tabular}{|c|c|c|c|c|}
\hline Variables & $\begin{array}{c}\text { (1) } \\
\text { OLS }\end{array}$ & $\begin{array}{c}\text { (2) } \\
\text { 1st stage: } \\
\text { Only child }\end{array}$ & $\begin{array}{c}(3) \\
\text { 2nd stage: } \\
\text { Myopia }\end{array}$ & $\begin{array}{c}\text { (4) } \\
\text { OLS: same } \\
\text { sample }\end{array}$ \\
\hline \multicolumn{5}{|l|}{ Instrumental variable } \\
\hline \multirow[t]{2}{*}{ First birth = boy } & & $0.22 * * *$ & & \\
\hline & & $(0.0099)$ & & \\
\hline \multirow[t]{2}{*}{ Fine in years of income } & & $0.020 * *$ & & \\
\hline & & $(0.0076)$ & & \\
\hline \multirow[t]{2}{*}{ Only-child } & $0.026^{* * *}$ & & $0.091^{*}$ & $0.017 *$ \\
\hline & $(0.0094)$ & & $(0.055)$ & $(0.010)$ \\
\hline \multirow[t]{2}{*}{ Boy } & $-0.098 * * *$ & $-0.063 * * *$ & $-0.10 * * *$ & $-0.094 * * *$ \\
\hline & $(0.0075)$ & $(0.0096)$ & $(0.0099)$ & $(0.0081)$ \\
\hline \multirow[t]{2}{*}{ Age } & -0.0086 & $-0.12 *$ & -0.043 & -0.049 \\
\hline & $(0.069)$ & $(0.065)$ & $(0.083)$ & $(0.083)$ \\
\hline \multirow[t]{2}{*}{ Age squared } & 0.010 & 0.34 & 0.14 & 0.15 \\
\hline & $(0.23)$ & $(0.22)$ & $(0.28)$ & $(0.28)$ \\
\hline \multirow[t]{2}{*}{ Han ethnicity } & 0.013 & 0.011 & 0.0071 & 0.0078 \\
\hline & $(0.019)$ & $(0.017)$ & $(0.021)$ & $(0.021)$ \\
\hline \multirow[t]{2}{*}{ 9th grade dummy } & $0.14^{* * *}$ & $0.078 * * *$ & $0.13^{* * *}$ & $0.13 * * *$ \\
\hline & $(0.014)$ & $(0.012)$ & $(0.016)$ & $(0.015)$ \\
\hline \multirow[t]{2}{*}{ Rural hukou } & $-0.033 * * *$ & $-0.15 * * *$ & -0.018 & $-0.030 * * *$ \\
\hline & $(0.0093)$ & $(0.0088)$ & $(0.013)$ & $(0.010)$ \\
\hline \multirow[t]{2}{*}{ Local resident } & 0.0083 & $0.16^{* * *}$ & 0.0053 & 0.017 \\
\hline & $(0.011)$ & $(0.011)$ & $(0.015)$ & $(0.012)$ \\
\hline \multirow[t]{2}{*}{ Any serious disease before primary school } & -0.0066 & -0.00033 & -0.0069 & -0.0071 \\
\hline & $(0.014)$ & $(0.012)$ & $(0.015)$ & $(0.015)$ \\
\hline \multirow[t]{2}{*}{ Education of father } & 0.0016 & $0.0091 * * *$ & 0.00047 & 0.0011 \\
\hline & $(0.0018)$ & $(0.0017)$ & $(0.0020)$ & $(0.0019)$ \\
\hline \multirow[t]{2}{*}{ Education of mother } & $0.0029 *$ & $0.015^{* * *}$ & 0.0024 & $0.0036 * *$ \\
\hline & $(0.0016)$ & $(0.0014)$ & $(0.0019)$ & $(0.0017)$ \\
\hline \multirow[t]{2}{*}{ Party member } & 0.018 & $0.060 * * *$ & $0.026^{* *}$ & $0.030 * *$ \\
\hline & $(0.012)$ & $(0.010)$ & $(0.013)$ & $(0.013)$ \\
\hline \multirow[t]{2}{*}{ Professional occupation (father) } & $0.032 * * *$ & 0.015 & $0.033 * * *$ & $0.034 * * *$ \\
\hline & $(0.012)$ & $(0.010)$ & $(0.012)$ & $(0.012)$ \\
\hline \multirow[t]{2}{*}{ Professional occupation (mother) } & 0.0057 & $0.069 * * *$ & -0.0060 & -0.00080 \\
\hline & $(0.013)$ & $(0.011)$ & $(0.014)$ & $(0.014)$ \\
\hline \multirow[t]{2}{*}{ Economic condition: poor } & 0.00080 & 0.019 & -0.0032 & -0.0014 \\
\hline & $(0.022)$ & $(0.020)$ & $(0.025)$ & $(0.025)$ \\
\hline \multirow[t]{2}{*}{ Economic condition: average } & 0.0074 & $0.042 * *$ & 0.00047 & 0.0038 \\
\hline & $(0.022)$ & $(0.020)$ & $(0.024)$ & $(0.024)$ \\
\hline \multirow[t]{2}{*}{ Economic condition: rich } & -0.021 & -0.015 & -0.020 & -0.022 \\
\hline & $(0.027)$ & $(0.025)$ & $(0.030)$ & $(0.030)$ \\
\hline \multirow[t]{2}{*}{ Economic condition: very rich } & $-0.14 *$ & -0.051 & -0.12 & -0.13 \\
\hline & & & & 33 \\
\hline
\end{tabular}




\begin{tabular}{lcccc} 
& $(0.081)$ & $(0.071)$ & $(0.087)$ & $(0.087)$ \\
Dibao subsidy & $-0.025^{*}$ & 0.00035 & $-0.025^{*}$ & $-0.025^{*}$ \\
Sick/disabled household members & $(0.013)$ & $(0.012)$ & $(0.015)$ & $(0.015)$ \\
& $0.024^{* *}$ & -0.00090 & $0.022^{*}$ & $0.022^{*}$ \\
Tap water & $(0.012)$ & $(0.011)$ & $(0.013)$ & $(0.013)$ \\
& 0.017 & $0.021^{*}$ & 0.021 & 0.023 \\
Improved sanitation facilities & $(0.013)$ & $(0.012)$ & $(0.015)$ & $(0.015)$ \\
& $0.031^{* * *}$ & 0.0038 & $0.028^{* *}$ & $0.028^{* *}$ \\
Constant & $(0.012)$ & $(0.010)$ & $(0.013)$ & $(0.013)$ \\
& 0.64 & $1.14^{* *}$ & 0.84 & 0.91 \\
County/district fixed effect & $(0.51)$ & $(0.48)$ & $(0.62)$ & $(0.62)$ \\
Observations & Yes & Yes & Yes & Yes \\
R-squared & 16,226 & 13,938 & 13,938 & 13,938 \\
\hline
\end{tabular}

Notes: The sample used in columns (3) and (4) are the same. Robust standard errors in parentheses. *** $\mathrm{p}<0.01, * * \mathrm{p}<0.05, * \mathrm{p}<0.1$. 
TABLE 5 Impact of only child on the degree of myopia

\begin{tabular}{|c|c|c|c|c|}
\hline Variables & $\begin{array}{c}(1) \\
\text { Normal }\end{array}$ & $\begin{array}{c}(2) \\
\text { Mild } \\
\text { nearsighted } \\
\text { ness }\end{array}$ & $\begin{array}{c}\text { (3) } \\
\text { Moderate } \\
\text { nearsightedness }\end{array}$ & $\begin{array}{c}(4) \\
\text { Severe } \\
\text { nearsightedness }\end{array}$ \\
\hline \multicolumn{5}{|l|}{ Panel A: Left eye } \\
\hline Only-child & $\begin{array}{l}-0.036^{*} \\
(0.019)\end{array}$ & $\begin{array}{l}0.015 * \\
(0.008)\end{array}$ & $\begin{array}{l}0.018 * \\
(0.009)\end{array}$ & $\begin{array}{l}0.0029 * \\
(0.0015)\end{array}$ \\
\hline $\begin{array}{l}\text { County/district fixed } \\
\text { effect }\end{array}$ & Yes & Yes & Yes & Yes \\
\hline Obs. & 14,032 & 14,032 & 14,032 & 14,032 \\
\hline \multicolumn{5}{|l|}{ Panel B: Right eye } \\
\hline Only-child & $\begin{array}{c}-0.039 * * \\
(0.018)\end{array}$ & $\begin{array}{l}0.015^{* *} \\
(0.0072)\end{array}$ & $\begin{array}{l}0.020 * * \\
(0.0096)\end{array}$ & $\begin{array}{l}0.0035^{* *} \\
(0.0017)\end{array}$ \\
\hline $\begin{array}{l}\text { County/district fixed } \\
\text { effect }\end{array}$ & Yes & Yes & Yes & Yes \\
\hline Obs. & 14,032 & 14,032 & 14,032 & 14,032 \\
\hline
\end{tabular}


TABLE 6 Robustness checks of birth order effect

\begin{tabular}{|c|c|c|c|c|}
\hline & (1) & (2) & (3) & (4) \\
\hline Variables & IV & Nonlinearity: OLS & IV & IV \\
\hline \multirow[t]{2}{*}{ No. of siblings } & -0.056 & & & $-0.14 *$ \\
\hline & $(0.035)$ & & & $(0.072)$ \\
\hline \multirow[t]{2}{*}{$\#$ of siblings $=1$} & & $-0.021 * *$ & & \\
\hline & & $(0.0096)$ & & \\
\hline \multirow[t]{2}{*}{$\#$ of siblings $=2$} & & $-0.047 * * *$ & & \\
\hline & & $(0.015)$ & & \\
\hline \multirow[t]{2}{*}{$\#$ of siblings $=3$} & & $-0.090 * * *$ & & \\
\hline & & $(0.029)$ & & \\
\hline \multirow[t]{2}{*}{$\#$ of siblings $=4$} & & -0.017 & & \\
\hline & & $(0.052)$ & & \\
\hline \multirow[t]{2}{*}{$\#$ of siblings $=5$} & & 0.0034 & & \\
\hline & & $(0.071)$ & & \\
\hline \multirow[t]{2}{*}{ Birth order } & & & -0.023 & \\
\hline & & & $(0.018)$ & \\
\hline \multirow[t]{2}{*}{ Birth order $=$ middle child } & & & & $0.19 *$ \\
\hline & & & & $(0.11)$ \\
\hline \multirow[t]{2}{*}{ Birth order = last-born } & & & & $0.077^{*}$ \\
\hline & & & & $(0.040)$ \\
\hline \multirow[t]{2}{*}{ Constant } & 0.94 & 0.62 & 0.95 & 0.93 \\
\hline & $(0.62)$ & $(0.52)$ & $(0.62)$ & $(0.63)$ \\
\hline County/district fixed effects & Yes & Yes & Yes & Yes \\
\hline Observations & 13,938 & 15,993 & 13,938 & 13,938 \\
\hline R-squared & 0.082 & 0.086 & 0.083 & 0.069 \\
\hline
\end{tabular}

Notes: The reference group of the number of siblings in column (2) is single child. The reference group of birth order in column (4) is the first-born. The number of siblings in columns (1) and (4) is instrumented with the gender of the first birth and provincial fine rate. The birth order in column (3) is also instrumented with the gender of the first birth and provincial fine rates. All regressions include both individual and household characteristics (coefficient estimates not reported). Robust standard errors in parentheses. $* * * \mathrm{p}<0.01, * * \mathrm{p}<0.05, * \mathrm{p}<0.1$. 
TABLE 7 Heterogeneous impacts of only child on myopia

\begin{tabular}{|c|c|c|c|c|c|c|}
\hline Variables & $\begin{array}{l}(1) \\
\text { Girl }\end{array}$ & $\begin{array}{l}(2) \\
\text { Boy }\end{array}$ & $\begin{array}{c}(3) \\
\text { 7th graders }\end{array}$ & $\begin{array}{c}(4) \\
\text { 9th graders }\end{array}$ & $\begin{array}{c}\text { (5) } \\
\text { High income } \\
\text { households }\end{array}$ & $\begin{array}{c}\text { (6) } \\
\text { Low income } \\
\text { households }\end{array}$ \\
\hline Only-child & $\begin{array}{c}0.032 \\
(0.085)\end{array}$ & $\begin{array}{c}0.039 \\
(0.033)\end{array}$ & $\begin{array}{c}0.14 * \\
(0.079)\end{array}$ & $\begin{array}{c}0.012 \\
(0.078)\end{array}$ & $\begin{array}{c}0.056 \\
(0.060)\end{array}$ & $\begin{array}{l}0.22 * \\
(0.13)\end{array}$ \\
\hline Constant & $\begin{array}{l}-0.48 \\
(0.91)\end{array}$ & $\begin{array}{c}1.81 * * \\
(0.85)\end{array}$ & $\begin{array}{c}1.58 \\
(1.66)\end{array}$ & $\begin{array}{c}2.62 \\
(1.90)\end{array}$ & $\begin{array}{c}0.66 \\
(0.72)\end{array}$ & $\begin{array}{c}1.25 \\
(1.33)\end{array}$ \\
\hline Observations & 6,871 & 7,067 & 7,002 & 6,936 & 11,241 & 2,697 \\
\hline R-squared & 0.069 & 0.090 & 0.068 & 0.076 & 0.079 & 0.069 \\
\hline County/district fixed effects & Yes & Yes & Yes & Yes & Yes & Yes \\
\hline P-value & \multicolumn{2}{|c|}{0.478} & \multicolumn{2}{|c|}{0.152} & \multicolumn{2}{|c|}{0.166} \\
\hline
\end{tabular}

Notes: All regressions are estimated using instrumental variables and include both individual and household characteristics (coefficient estimates not reported). Robust standard errors in parentheses. $* * * \mathrm{p}<0.01,{ }^{*} * \mathrm{p}<0.05, * \mathrm{p}<0.1$. 
TABLE 8 Impacts of only-child on expectations of parents and school quality

(1) (8) (16)

Expectation: Expectation: School

\begin{tabular}{|c|c|c|c|}
\hline Variables & score & degree & quality \\
\hline \multirow[t]{2}{*}{ Only-child } & $0.11 * *$ & $0.11 *$ & $0.16^{* * *}$ \\
\hline & $(0.054)$ & $(0.062)$ & $(0.056)$ \\
\hline \multirow[t]{2}{*}{ Boy } & $-0.16^{* * *}$ & $-0.16 * * *$ & 0.011 \\
\hline & $(0.018)$ & $(0.019)$ & $(0.019)$ \\
\hline \multirow[t]{2}{*}{ Age } & $-0.49 * * *$ & $-0.83 * * *$ & $-0.42 * *$ \\
\hline & $(0.17)$ & $(0.17)$ & $(0.17)$ \\
\hline \multirow[t]{2}{*}{ Age squared } & $1.31 * *$ & $2.45 * * *$ & $1.14 * *$ \\
\hline & $(0.57)$ & $(0.56)$ & $(0.58)$ \\
\hline \multirow[t]{2}{*}{ Han ethnicity } & 0.041 & 0.071 & $0.11 * *$ \\
\hline & $(0.044)$ & $(0.047)$ & $(0.047)$ \\
\hline \multirow[t]{2}{*}{ 9th grade dummy } & -0.018 & -0.024 & $0.21 * * *$ \\
\hline & $(0.032)$ & $(0.034)$ & $(0.034)$ \\
\hline \multirow[t]{2}{*}{ Rural hukou } & $0.093 * * *$ & -0.013 & $-0.24 * * *$ \\
\hline & $(0.022)$ & $(0.024)$ & $(0.024)$ \\
\hline \multirow[t]{2}{*}{ Local resident } & $-0.097 * * *$ & $-0.087 * * *$ & 0.030 \\
\hline & $(0.027)$ & $(0.027)$ & $(0.028)$ \\
\hline \multirow[t]{2}{*}{ Any serious disease before primary school } & -0.027 & -0.021 & $-0.053^{*}$ \\
\hline & $(0.032)$ & $(0.033)$ & $(0.032)$ \\
\hline \multirow[t]{2}{*}{ Education of father } & $0.030 * * *$ & $0.054 * * *$ & $0.049 * * *$ \\
\hline & $(0.0042)$ & $(0.0044)$ & $(0.0045)$ \\
\hline \multirow[t]{2}{*}{ Education of mother } & 0.0017 & $0.023 * * *$ & $0.033 * * *$ \\
\hline & $(0.0039)$ & $(0.0041)$ & $(0.0041)$ \\
\hline \multirow[t]{2}{*}{ Party member } & $-0.047 *$ & -0.00091 & $0.055^{*}$ \\
\hline & $(0.028)$ & $(0.029)$ & $(0.031)$ \\
\hline \multirow[t]{2}{*}{ Professional occupation (father) } & 0.014 & $0.11 * * *$ & $0.10^{* * *}$ \\
\hline & $(0.027)$ & $(0.028)$ & $(0.030)$ \\
\hline \multirow[t]{2}{*}{ Professional occupation (mother) } & 0.015 & $0.13 * * *$ & $0.19 * * *$ \\
\hline & $(0.031)$ & $(0.033)$ & $(0.035)$ \\
\hline \multirow[t]{2}{*}{ Economic condition: poor } & 0.043 & 0.045 & $0.10 * *$ \\
\hline & $(0.053)$ & $(0.057)$ & $(0.048)$ \\
\hline \multirow[t]{2}{*}{ Economic condition: average } & 0.017 & 0.029 & $0.25 * * *$ \\
\hline & $(0.052)$ & $(0.056)$ & $(0.047)$ \\
\hline \multirow[t]{2}{*}{ Economic condition: rich } & 0.023 & 0.099 & $0.37 * * *$ \\
\hline & $(0.064)$ & $(0.067)$ & $(0.064)$ \\
\hline \multirow[t]{2}{*}{ Economic condition: very rich } & -0.13 & 0.12 & 0.13 \\
\hline & $(0.19)$ & $(0.22)$ & $(0.18)$ \\
\hline \multirow[t]{2}{*}{ Dibao subsidy } & $-0.10 * * *$ & $-0.14 * * *$ & $-0.11 * * *$ \\
\hline & $(0.030)$ & $(0.031)$ & $(0.030)$ \\
\hline \multirow[t]{2}{*}{ Sick/disabled household members } & 0.038 & 0.036 & -0.014 \\
\hline & $(0.027)$ & (0.029) & $(0.029)$ \\
\hline
\end{tabular}




\begin{tabular}{lccc} 
Tap water & -0.029 & -0.0037 & $0.21^{* * *}$ \\
& $(0.030)$ & $(0.033)$ & $(0.031)$ \\
Improved sanitation facilities & 0.029 & $0.081^{* * *}$ & $0.077^{* * *}$ \\
& $(0.027)$ & $(0.028)$ & $(0.027)$ \\
\hline County/district fixed effect & Yes & Yes & Yes \\
Observations & 16,327 & 16,323 & 16,319 \\
Log pseudolikelihood & -26373.64 & -24664.54 & -21713.65 \\
\hline
\end{tabular}

Notes: All regressions are estimated using instrumental variables. Only-child indicator is instrumented with the gender of the first birth and provincial fine rates. Robust standard errors in parentheses. *** $\mathrm{p}<0.01, * * \mathrm{p}<0.05, * \mathrm{p}<0.1$. 
TABLE 9 Impact of only-child on time allocation

\begin{tabular}{|c|c|c|c|c|c|c|c|}
\hline Variables & $\begin{array}{c}(1) \\
\text { Sleep }\end{array}$ & $\begin{array}{c}(2) \\
\text { Homework } \\
\text {-teachers }\end{array}$ & $\begin{array}{c}(3) \\
\text { Homework } \\
\text {-parents }\end{array}$ & $\begin{array}{c}\text { (4) } \\
\text { TV hour }\end{array}$ & $\begin{array}{c}(5) \\
\text { Internet }\end{array}$ & $\begin{array}{c}(6) \\
\text { Extra-class }\end{array}$ & $\begin{array}{c}(7) \\
\text { Sports }\end{array}$ \\
\hline \multicolumn{8}{|c|}{ Panel A: Weekdays } \\
\hline Only-child & $\begin{array}{l}-0.14 \\
(0.11)\end{array}$ & $\begin{array}{l}-0.086 \\
(0.16)\end{array}$ & $\begin{array}{c}-0.14 \\
(0.097)\end{array}$ & $\begin{array}{l}0.095 \\
(0.11)\end{array}$ & $\begin{array}{l}-0.063 \\
(0.093)\end{array}$ & $\begin{array}{l}-0.014 \\
(0.056)\end{array}$ & $\begin{array}{c}0.14 \\
(0.091)\end{array}$ \\
\hline Constant & $\begin{array}{c}10.4 * * * \\
(1.25)\end{array}$ & $\begin{array}{c}1.57 \\
(1.76)\end{array}$ & $\begin{array}{l}-0.21 \\
(1.13)\end{array}$ & $\begin{array}{c}0.80 \\
(1.29)\end{array}$ & $\begin{array}{c}-1.93^{* *} \\
(0.92)\end{array}$ & $\begin{array}{c}-1.54 * * \\
(0.63)\end{array}$ & $\begin{array}{c}2.21^{* *} \\
(1.00)\end{array}$ \\
\hline Observations & 12,708 & 12,428 & 12,538 & 12,597 & 12,569 & 12,567 & 12,572 \\
\hline R-squared & 0.218 & 0.163 & 0.065 & 0.065 & 0.046 & 0.087 & 0.020 \\
\hline Panel B: Wee & & & & & & & \\
\hline Only-child & & $\begin{array}{l}-0.15 \\
(0.20)\end{array}$ & $\begin{array}{l}-0.21 * \\
(0.12)\end{array}$ & $\begin{array}{c}0.11 \\
(0.17)\end{array}$ & $\begin{array}{l}-0.14 \\
(0.16)\end{array}$ & $\begin{array}{c}-0.028 \\
(0.11)\end{array}$ & $\begin{array}{c}0.17 \\
(0.12)\end{array}$ \\
\hline Constant & & $\begin{array}{c}0.51 \\
(2.14)\end{array}$ & $\begin{array}{c}1.48 \\
(1.36)\end{array}$ & $\begin{array}{c}2.02 \\
(1.73)\end{array}$ & $\begin{array}{l}-0.54 \\
(1.59)\end{array}$ & $\begin{array}{c}-2.97 * * \\
(1.33)\end{array}$ & $\begin{array}{c}3.40 * * * \\
(1.22)\end{array}$ \\
\hline Observations & & 11,593 & 11,764 & 11,673 & 11,711 & 11,726 & 11,591 \\
\hline R-squared & & 0.088 & 0.070 & 0.044 & 0.080 & 0.219 & 0.040 \\
\hline
\end{tabular}

Notes: All regressions are estimated using instrumental variables and include both individual and household characteristics (coefficient estimates not reported). Robust standard errors in parentheses. $* * * \mathrm{p}<0.01, * * \mathrm{p}<0.05, * \mathrm{p}<0.1$. 
TABLE 10 Only-child, expectation of parents, time allocation and myopia

\begin{tabular}{|c|c|}
\hline Variables & $\begin{array}{c}(1) \\
\text { Myopia }\end{array}$ \\
\hline Only-child & $\begin{array}{c}0.089 \\
(0.069)\end{array}$ \\
\hline Boy & $\begin{array}{c}-0.098 * * * \\
(0.012)\end{array}$ \\
\hline Age & $\begin{array}{l}-0.028 \\
(0.098)\end{array}$ \\
\hline Age squared & $\begin{array}{l}0.091 \\
(0.33)\end{array}$ \\
\hline Han ethnicity & $\begin{array}{l}0.0098 \\
(0.025)\end{array}$ \\
\hline 9th grade dummy & $\begin{array}{c}0.12 * * * \\
(0.019)\end{array}$ \\
\hline Rural hukou & $\begin{array}{l}-0.017 \\
(0.016)\end{array}$ \\
\hline Local resident & $\begin{array}{l}0.0097 \\
(0.017)\end{array}$ \\
\hline Any serious disease before primary school & $\begin{array}{c}0.00099 \\
(0.018)\end{array}$ \\
\hline Education of father & $\begin{array}{l}0.00021 \\
(0.0023)\end{array}$ \\
\hline Education of mother & $\begin{array}{c}0.0025 \\
(0.0023)\end{array}$ \\
\hline Party member & $\begin{array}{c}0.022 \\
(0.015)\end{array}$ \\
\hline Professional occupation (father) & $\begin{array}{c}0.028 * * \\
(0.014)\end{array}$ \\
\hline Professional occupation (mother) & $\begin{array}{l}-0.016 \\
(0.017)\end{array}$ \\
\hline Economic condition: poor & $\begin{array}{r}-0.0053 \\
(0.031)\end{array}$ \\
\hline Economic condition: average & $\begin{array}{l}-0.012 \\
(0.030)\end{array}$ \\
\hline Economic condition: rich & $\begin{array}{l}-0.031 \\
(0.036)\end{array}$ \\
\hline Economic condition: very rich & $\begin{array}{l}-0.11 \\
(0.10)\end{array}$ \\
\hline Dibao subsidy & $\begin{array}{l}-0.023 \\
(0.018)\end{array}$ \\
\hline Sick/disabled household members & $\begin{array}{c}0.022 \\
(0.015)\end{array}$ \\
\hline
\end{tabular}


Tap water

0.021

$(0.018)$

Improved sanitation facilities

$0.027 *$

$(0.015)$

Expectation: academic performance

$0.019 * * *$

$(0.0057)$

Expectation: educational attainment

$0.016 * * *$

$(0.0062)$

School quality

$0.014 *$

$(0.0073)$

Sleeping hours

$-0.0046$

$(0.0053)$

Hours spent on homework assigned by teachers

$0.0081 * *$

$(0.0041)$

$-0.00043$

Hours spend on homework assigned by parents

$(0.0054)$

Hours spent on surfing the internet

$0.012^{*}$

$(0.0072)$

$-0.0090$

Hours spent on sports

$(0.0068)$

Constant

0.56

(0.74)

County/district fixed effect

Yes

Observations

10,201

R-squared

0.081

Notes: Robust standard errors in parentheses. $* * * \mathrm{p}<0.01, * * \mathrm{p}<0.05, * \mathrm{p}<0.1$. 


\section{Appendix A. Supplementary Figures and Tables}
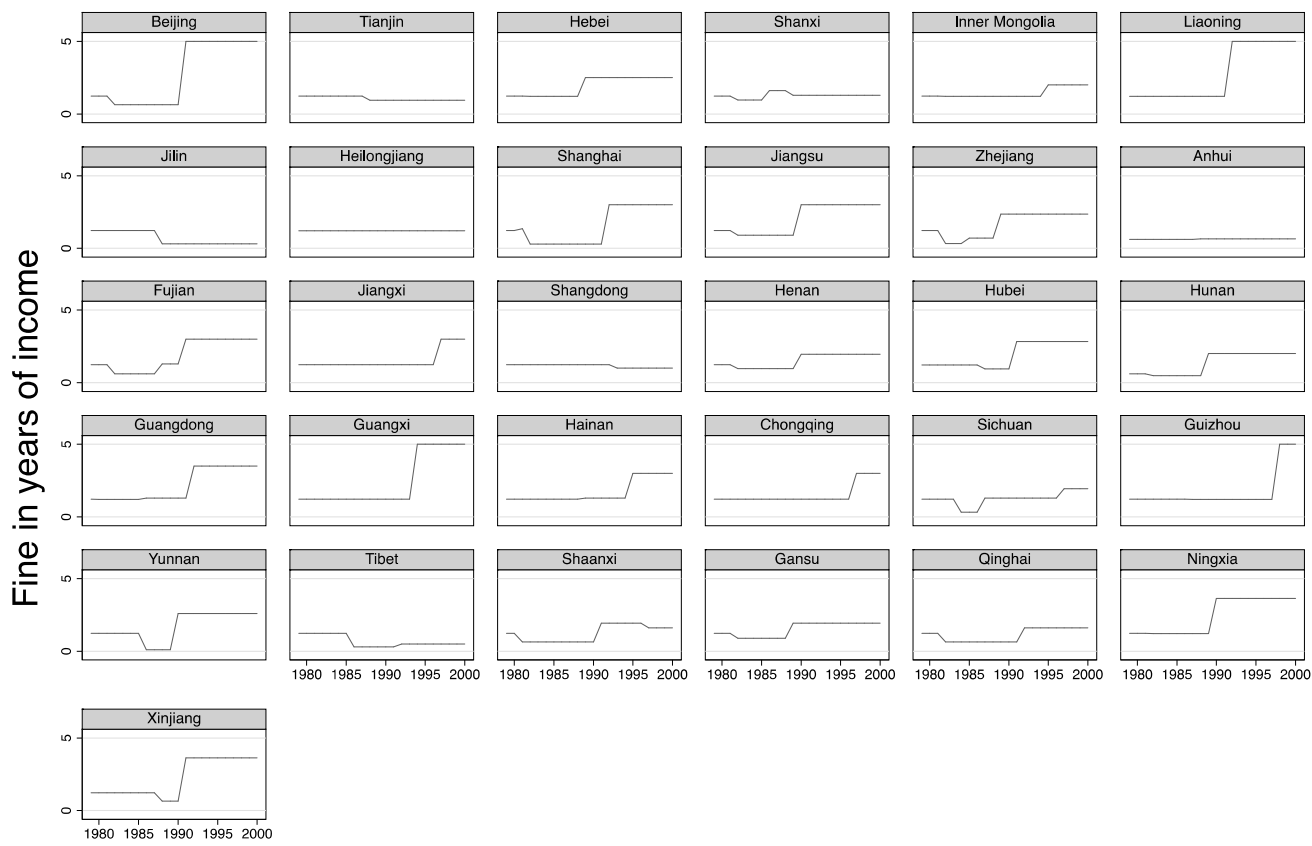

Graphs by province

Birth year

FIGURE A.1 One-child policy regulatory fine rates in 1980-2000, by province. Source: Ebenstein (2010). 
TABLE A.1 Having an eye examination

\begin{tabular}{lcc}
\hline Variables & $\begin{array}{c}(1) \\
\text { Having an eye } \\
\text { examination }\end{array}$ & $\begin{array}{c}(2) \\
\text { Having an eye } \\
\text { examination }\end{array}$ \\
\hline First birth = boy & -0.010 & \\
Fine in years of income & $(0.012)$ & \\
Constant & & -0.040 \\
& & $(0.041)$ \\
County/district fixed effect & 1.54 & 1.67 \\
Observations & $(1.14)$ & $(1.16)$ \\
R-squared & Yes & Yes \\
\hline
\end{tabular}

Notes: The dependent variable is an indicator of having an eye examination. Only the 7th graders report whether they have had eye examinations recently. The regressions are thus based on the sample of the 7th graders. All regressions include both individual and household characteristics. Robust standard errors in parentheses. $* * * \mathrm{p}<0.01, * * \mathrm{p}<0.05, * \mathrm{p}<0.1$. 
TABLE A.2 Severe nearsightedness

\begin{tabular}{lcc}
\hline Variables & $(1)$ & $(2)$ \\
& 7th Graders & 9 th Graders \\
Only-child & 0.0023 & $0.023^{*}$ \\
Constant & $(0.0039)$ & $(0.013)$ \\
& 0.092 & -0.11 \\
& $(0.15)$ & $(0.20)$ \\
Observations & & 6,961 \\
R-squared & 7,060 & 0.005 \\
County/district fixed effects & 0.009 & Yes \\
\hline
\end{tabular}

Notes: The dependent variable is an indicator of having severe nearsightedness (-6.00 diopters or higher). Only the 7th graders report whether they wear glasses or not. The regressions are thus based on the sample of the 7th graders. All regressions include both individual and household characteristics. Robust standard errors in parentheses. $* * * \mathrm{p}<0.01, * * \mathrm{p}<0.05,{ }^{*} \mathrm{p}<0.1$. 